\title{
Erosion Wear Behavior of SiC Nano powder Filled Flax and Sisal Fabric Hybrid Composites with Taguchi Experimental Design
}

\author{
Ganesh Kalagi, Rajashekar Patil
}

\begin{abstract}
This work is carried out to find out the erosion wear characteristics of unfilled and also SiC nanopowder filled flax and sisal fabric hybrid composites (FSHC). Effect of different parameters such as filler content, impingement angle and erodent size on the erosion wear behavior of hybrid composite has been studied using Taguchi method. Significant control factors altering the erosion rate have been evaluated through outstanding execution ANOVA. The experimental outcomes are recognized to be in acceptable accord with the assumptive values. This study indicates that erosion wear resistance increases as SiC nanopowder increases in FSHC.
\end{abstract}

Keywords: Flax fabric, sisal fabric, SiC nanopowder, Erosion wear, Taguchi method.

\section{INTRODUCTION}

Polymer composites are using in many applications of engineering systems. These materials having excellent properties, simple process ability and no secondary processes are required. Pipeline carrying sand particles, rotor blades and wind turbine blades are some of the applications of polymer composite materials. In such applications, one crucial characteristic is the erosion wear behavior, as these parts are used in dusty environments [1-2]. This is one of the major factor made most of the researchers to study on erosion characteristics of polymers and relevant composites has been intensively studied. In order to select materials for the design of structural components, it is very important to understand the impacts of all variables such as content, composition, orientation and etc. on wear rate [3]. Zahavi and Schmitt [4] were noticed that at $45^{\circ}$ to $60^{\circ}$ impingement angle of particles on glass fiber reinforced composites showed semi ductile erosion behavior with a maximum weight loss. Tilly and Sage [5] investigated the influence of various parameters on CFR nylon composites, and GFR plastic composites. These composites behaved in an ideally brittle manner.Kim et al. [6]

Revised Manuscript Received on 30 July 2019.

* Correspondence Author

Ganesh Kalagi* Sr. Assistant Professor, Department of Mechanical Engineering , Shri Madhwa Vadiraja Institute of Technology \& Management, Bantakal, India Email: ganeshkalagi082@gmail.com

Rajashekar Patil, Professor, Head of the department, School of Mechanical Engineering, CMR University, Chagalahatti, Bengaluru, India Email: eashan123@gmail.com

(C) The Authors. Published by Blue Eyes Intelligence Engineering and Sciences Publication (BEIESP). This is an open access article under the CC-BY-NC-ND license http://creativecommons.org/licenses/by-nc-nd/4.0/ scrutinized erosion attributes of epoxy based unidirectional as well as multidirectional CFR plastic composites with $\mathrm{SiC}$ particles were used. This was resulted in ductile behavior of materials at impingement angle of 15 to $30^{\circ}$. Another study was accomplished by Mahapatra and Patnaik [7] were examined the erosion wear characterizations of multiphase hybrid composites consisting of PE with GF and ceramic powders, and also compared the impact of three different fillers such as cement by pass dust, alumina, and $\mathrm{SiC}$ on the wear characterizations of GF reinforced PE composites. The erosion tests were conducted in air- jet type test rig, after which design of experiments were made using Taguchi strategy approach. The Taguchi strategy was used to set ideal parameters that led to minimization of the erosion rate. The results were indicated that erodent size; filler content; impingement angle; and impact velocity influence the wear rate significantly. Rajesh et al. [8] revealed that $30^{\circ}$ angle more erosion wear than at 90 for SiC filled polyamides. The study by Pool et al. [1] investigated the behavior of graphite and aramid reinforcing with polyphenylene under erosion. Biswas et al. [9] established a mathematical model to study the parameters affecting erosion using Taguchi method analysis. The filler content, erodent temperature, angle of erodent impingement, and velocity are found to have substantial influence on material loss due to erosion. A number of erosion modes often acknowledged in literature work such as brittle and ductile. Crack formation in composite suggests that brittle erosion, while ductile erosion deals with material removal due to cutting as well as ploughing [1]. In case, when maximum erosion occurs at low angle it is considered to be as ductile erosion and conversely, if maximum erosion is found at high impingement angle, then the brittle mode is assumed. Anup gupta et al. [10] were studied the erosion wear behavior of bamboo fiber reinforced polymer composites. Maximum erosion occurred at $60-75^{\circ}$ for bamboo fiber reinforced composites. So the mode of erosion wear was neither brittle nor ductile, it behaved like semi brittle or semi ductile mode of erosion wear.

\section{METHODOLOGY}

In the present research work natural fibers such as flax and sisal fabrics are used as reinforcement in the epoxy matrix to fabricate a set of hybrid composites. SiC nanopowder of size $80 \mathrm{~nm}$ is utilized as filler material at different loadings.

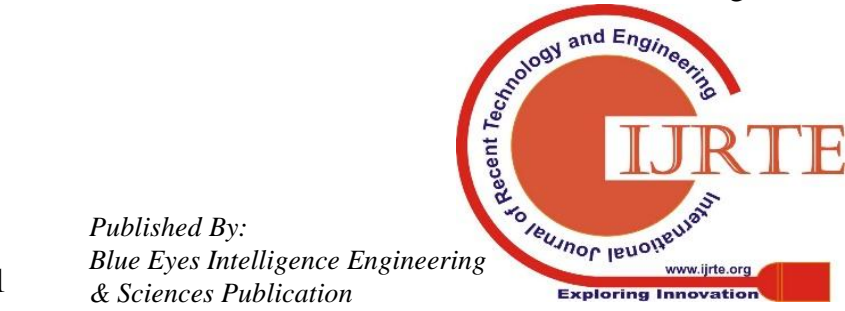


Matrix material LY556 resin was chosen which is blended with hardener The properties of matrix and reinforcement are given in Table 1.

Table 1 : Properties of Reinforcement and Matrix Materials

\begin{tabular}{|c|c|c|c|c|}
\hline $\begin{array}{c}\text { Reinforceme } \\
\text { nt / Matrix }\end{array}$ & $\begin{array}{c}\text { Densit } \\
\mathbf{y}- \\
(\mathrm{gm} / \mathrm{c} \\
\left.\mathbf{m}^{3}\right)\end{array}$ & $\begin{array}{c}\text { Failure } \\
\text { strain - (\%) }\end{array}$ & $\begin{array}{c}\text { Tensile } \\
\text { Strength - } \\
\text { (MPa) }\end{array}$ & $\begin{array}{c}\text { Youngs } \\
\text { Modulus - } \\
\text { (GPa) }\end{array}$ \\
\hline Flax fiber & 1.5 & 1.33 & 800 & 60 \\
\hline Sisal fiber & 1.3 & 2 & 688 & 35 \\
\hline $\mathrm{SiC}$ & 3.1 & - & 320 & 410 \\
\hline \multicolumn{5}{|l|}{ nanopowd } \\
\hline \multicolumn{5}{|l|}{ er } \\
\hline Epoxy & 1.15 & - & 95 & 3.5 \\
\hline
\end{tabular}

\section{Composite preparation}

Hybrid composites are developed by layers of flax and also sisal fabric using resin as matrix material by varying weight portions. The various other hybrid composites with $\mathrm{SiC}$ nanopowder were manufactured by differing reinforcement as well as matrix weight faction. The classification, stacking sequences as well as detailed structure of the composites planned in this reserach are provided in Table 2. The hand-layup process is used in this research to fabricate slabs of all composites. SiC nanopowder was blended in the epoxy material before flax as well as sisal fabrics were enhanced with matrix resin material. The composites were prepared in 2 various collections. In initial collection, the SiC nanopowder (0, 5, $10 \mathrm{wt} \%)$ were used as filler product in 15/15 wt\% FSHC. In second collection SiC nanopowder (0, 5, $10 \mathrm{wt} \%)$ were made use as filler material in 20/20 wt\% FSHC.

Table 2: Composition of fiber aad matrix of hybrid composites.

\begin{tabular}{clccc}
\hline Designation & $\begin{array}{c}\text { Stacking } \\
\text { Sequence }\end{array}$ & $\begin{array}{c}\text { flax } \\
\text { fabric }\end{array}$ & $\begin{array}{c}\text { sisal } \\
\text { fabric }\end{array}$ & $\begin{array}{c}\text { SiC } \\
\text { nanopowder }\end{array}$ \\
& & Wt \% & $\begin{array}{c}\text { Wt } \\
\mathbf{\%}\end{array}$ & Wt \% \\
\hline A & FSFSFS & 15 & 15 & 0 \\
B & FSFSFSFS & 20 & 20 & 0 \\
C & FSFSFS & 15 & 15 & 5 \\
D & FSFSFS & 15 & 15 & 10 \\
E & FSFSFSFS & 20 & 20 & 5 \\
F & FSFSFSFS & 20 & 20 & 10 \\
\hline
\end{tabular}

\section{Erosion wear test}

The particular setup for the solid particle erosion wear put on test used in this research work is capable to creating reproducible erosive situations for examining erosion wear resistance of the prepared composite samples. ASTM G 76 standard was used to conduct the experiments. In this work, content of filler, impingement angle as well as erodent size with three levels are taken into consideration as parameters for the study of erosion behavior of composites. These three parameters each at three levels would certainly call for $3^{3}=27$ runs in a full factorial experiment. The plan of the experiments for erosion wear are shown in Table 3. The Taguchi approach is created for procedure optimization and identification of optimal combinations of factors for given responses. The $\mathrm{S} / \mathrm{N}$ ratio can be calculated using the below equation,

Smaller is the better: $\frac{s}{N}=-10 \log \frac{1}{n}\left(\sum Y^{2}\right)$

Where, $\mathrm{n}$ is the number of observations, $\mathrm{Y}$ is the respective characteristic. For minimum erosion rate the $\mathrm{S} / \mathrm{N}$ ratio comes under smaller is better, which can be computed by equation (1). The tests are conducted according to Table 3.

Table 3: Levels of variables used during experimentation to analyze erosion wear behavior

\begin{tabular}{lcccc}
\hline \multicolumn{1}{c}{ Control factor } & \multicolumn{3}{c}{ Level } \\
& I & II & III & Units \\
& & & & \\
\hline Filler content $-(\mathrm{A})$ & 0 & 5 & 10 & $\%$ \\
Erodent Size $-(\mathrm{B})$ & 300 & 425 & 600 & $\mu \mathrm{m}$ \\
$\begin{array}{l}\text { Angle of } \\
\text { impingement }-(\mathrm{C})\end{array}$ & 30 & 60 & 90 & degree \\
\hline
\end{tabular}

\section{Fixed parameters for erosion wear}

Erodent - Silica Sand, Velocity - 50 m/s, Temp: Ambient, Nozzle bore dia.: $3 \mathrm{~mm}$ and Standoff distance: $50 \mathrm{~mm}$.

\section{RESULT AND DISCUSSION}

\subsection{Effect of impingement angle}

Erosion wear has several wear mechanisms which are greatly regulated by various parameters but amongst which filler content, angle of impingement and particle size are most influencing parameters. Figure 1 shows the variation of erosion wear rate of composites at different angle and erodent size. It is noticed that erosion rate decreases as $\mathrm{SiC}$ nanopowder content increases in FSHC. However, $10 \mathrm{wt} \%$ SiC nanopowder filled 20/20 wt\% FSHC shown very low erosion rate compeered to other hybrid composites as shown in figure 1 . Peak erosion takes place at $60^{\circ}$. This is attributed to composite hardness increases with addition of $\mathrm{SiC}$ nano particles. This indicates that, the mode of wear is ductile in unfilled FSHC and semi ductile/semi brittle mode of erosion in $\mathrm{SiC}$ nanopowder FSHC. 


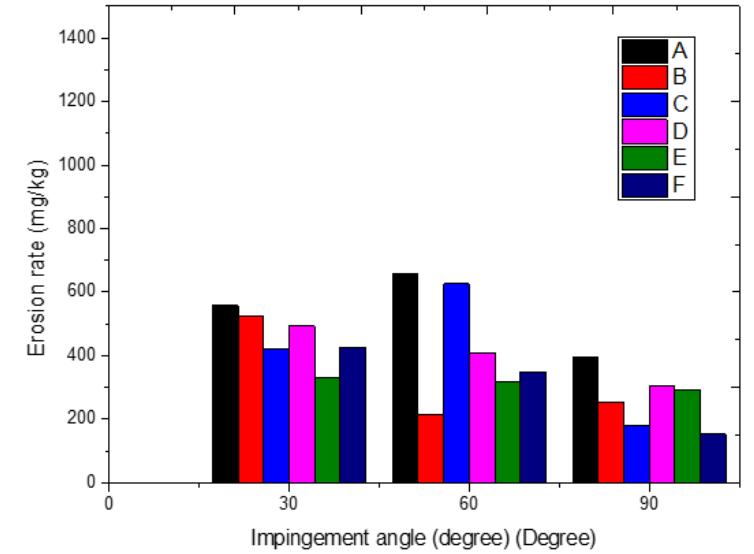

Figure 1: Impingement angle vs Erosion rate of hybrid composites

\section{Surface morphology of eroded hybrid composites}

Impingement angle is one of the most vital parameter in erosion mechanism. Figure shows the surface of unfilled FSHC eroded at different impingement angles. In figure 2. (a) shows the FSHC much material is removed at an impingement angle of $30^{\circ}$. Figure 2. (b) shows the erodent removed material at deepness of material and resulted in formation voids. When the impingement angle is changed to $90^{\circ}$, the features seen are quite different as shown in figure 2. (c). It shows plastic deformation of material. Figure 3 shows scanning electron micrographs of $\mathrm{SiC}$ nanopowder filled FSHC surface eroded at different angles. Figure 3. (a) shows eroded surface at angle of $30^{\circ}$. When impacting at such low angle, the hard erodent particles penetrate the surface area and also trigger removal of matrix material and resulted in fiber pull out from the material as shown in figure 3. (a). Figure 3. (b) shows eroded surface of SiC nanopowder filled FSHC at angle of $60^{\circ}$. It reveals that material elimination as a result of plastic deformation of matrix material with $\mathrm{SiC}$ nanopowder. When impingement angle is $90^{\circ}$ the matrix material gets softened which resulted in embedment of sand particles and hence reduced wear rate as shown in figure 3. (c).

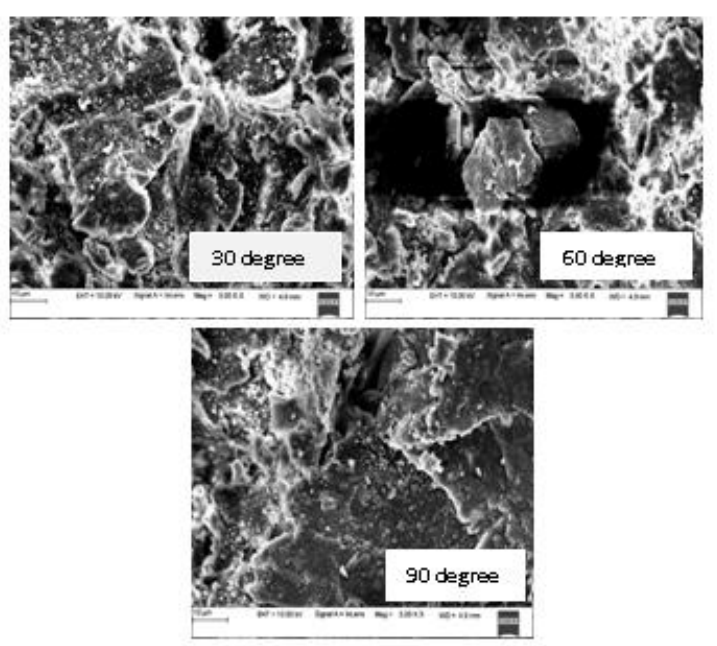

Figure 2: SEM micrographs of the eroded unfilled FSHC

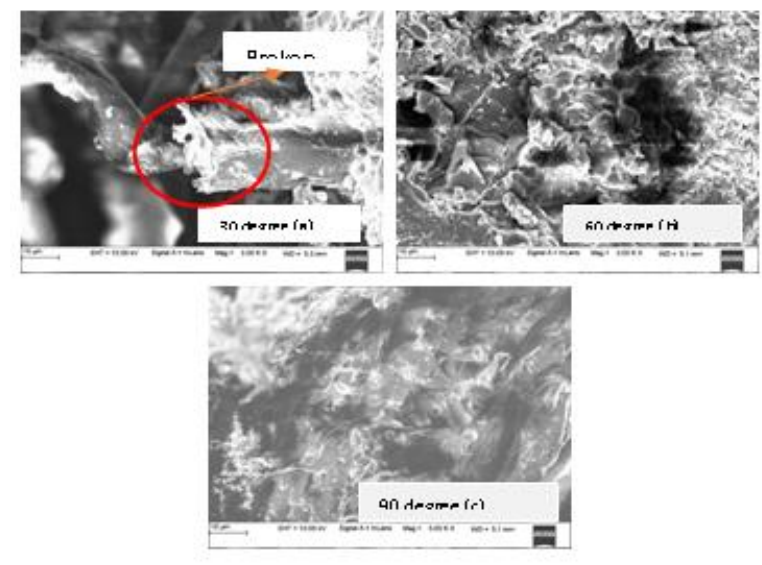

Figure 3: SEM micrographs of the eroded SiC nanopowder filled FSHC

Taguchi analysis

In Table 4, the last column strands for $\mathrm{S} / \mathrm{N}$ ratio of the erosion rate for 15/15 wt\% and also 20/20wt\% FSHC The overall mean for the $\mathrm{S} / \mathrm{N}$ ratio of the erosion rate is found to be $-49.3983 \mathrm{db}$ for $\mathrm{SiC}$ nanopowder filled 15/15 wt\% and $-56.1498 \mathrm{db}$ for SiC nanopowder filled 20/20 wt\% FSHC. The evaluation was made by using the software MINITAB 16. Evaluation of the result leads to the conclusion that factor combination of A3, B3, C3 gives minimum erosion rate as shown in figure 4. (a) for SiC nanopowder filled 15/15 wt\% hybrid composites and SiC nanopowder filled 20/20 wt\% FSHC the factor combination of A3, B2, C3 gives minimum erosion rate as shown in figure 4. (b). From Table 5, it can be observed for SiC nanopowder filled 15/15 wt\% FSHC composites, $\mathrm{SiC}$ nanopowder content $(\mathrm{P}=0.455)$ and Erodent dimension $(\mathrm{P}=0.474)$ have considerable impact on erosion rate whereas, impingement angle $(\mathrm{P}=0.045)$ has significant contribution over erosion rate. The interaction of $\mathrm{SiC}$ nanopowder content and erodent dimension $(\mathrm{P}=0.139)$ show significant contribution on the erosion rate. However, the remaining factors and also interactions fairly less significant contribution on erosion rate. Similarly, from Table 6, it can be observed for SiC nanopowder filled 20/20 wt\% FSHC, SiC nanopowder content $(\mathrm{P}=0.0075)$, Erodent size $(\mathrm{P}=0.0064)$ and impingement angle $(\mathrm{P}=0.057)$ have great influence on erosion rate. The interaction of $\mathrm{SiC}$ nanopowder content and erodent size $(\mathrm{P}=0.22)$ show significant contribution on the erosion rate but the remaining factors and interactions have relatively less significant contribution on erosion rate. 
Erosion Wear Behavior of SiC Nano powder Filled Flax and Sisal Fabric Hybrid Composites with Taguchi Experimental Design

Table 4: Comparison of erosion rates of SiC nanopowder filled 15/15 wt\% and 20/20 wt \% FSHC as per L27 orthogonal

\begin{tabular}{|c|c|c|c|c|c|c|c|}
\hline Sl.No. & $\begin{array}{l}\text { A } \\
(\%)\end{array}$ & $\begin{array}{c}\mathrm{B} \\
(\mu \mathrm{m})\end{array}$ & C (Degree) & $\begin{array}{c}\operatorname{Er}(15 / 15 \mathrm{wt} \%) \\
(\mathrm{mg} / \mathrm{kg})\end{array}$ & SNR & $\begin{array}{c}\operatorname{Er}(20 / 20 \text { wt\%) } \\
(\mathrm{mg} / \mathrm{kg})\end{array}$ & SNR \\
\hline 1 & 0 & 300 & 30 & 285.938 & -49.125 & 1323.438 & -62.434 \\
\hline 2 & 0 & 300 & 60 & 693.750 & -56.824 & 739.063 & -57.374 \\
\hline 3 & 0 & 300 & 90 & 437.500 & -52.820 & 426.562 & -52.600 \\
\hline 4 & 0 & 425 & 30 & 556.923 & -54.916 & 526.154 & -54.422 \\
\hline 5 & 0 & 425 & 60 & 658.462 & -56.371 & 212.308 & -46.539 \\
\hline 6 & 0 & 425 & 90 & 393.846 & -51.907 & 253.846 & -48.091 \\
\hline 7 & 0 & 600 & 30 & 379.104 & -51.575 & 544.776 & -54.724 \\
\hline 8 & 0 & 600 & 60 & 355.224 & -51.010 & 570.149 & -55.120 \\
\hline 9 & 0 & 600 & 90 & 77.612 & -37.799 & 510.448 & -54.159 \\
\hline 10 & 5 & 300 & 30 & 531.250 & -54.506 & 323.437 & -50.196 \\
\hline 11 & 5 & 300 & 60 & 489.063 & -53.787 & 589.062 & -55.403 \\
\hline 12 & 5 & 300 & 90 & 431.250 & -52.695 & 451.562 & -53.094 \\
\hline 13 & 5 & 425 & 30 & 421.538 & -52.497 & 492.308 & -53.845 \\
\hline 14 & 5 & 425 & 60 & 626.154 & -55.934 & 409.231 & -52.239 \\
\hline 15 & 5 & 425 & 90 & 181.538 & -45.179 & 303.077 & -49.631 \\
\hline 16 & 5 & 600 & 30 & 356.716 & -51.046 & 688.060 & -56.753 \\
\hline 17 & 5 & 600 & 60 & 358.209 & -51.083 & 432.836 & -52.726 \\
\hline 18 & 5 & 600 & 90 & 325.224 & -50.244 & 394.030 & -51.911 \\
\hline 19 & 10 & 300 & 30 & 234.375 & -47.398 & 284.375 & -49.078 \\
\hline 20 & 10 & 300 & 60 & 337.500 & -50.565 & 284.375 & -49.078 \\
\hline 21 & 10 & 300 & 90 & 171.875 & -44.704 & 293.750 & -49.360 \\
\hline 22 & 10 & 425 & 30 & 332.308 & -50.431 & 426.154 & -52.591 \\
\hline 23 & 10 & 425 & 60 & 318.462 & -50.061 & 347.692 & -50.824 \\
\hline 24 & 10 & 425 & 90 & 292.308 & -49.317 & 152.308 & -43.654 \\
\hline 25 & 10 & 600 & 30 & 389.552 & -51.811 & 520.896 & -54.335 \\
\hline 26 & 10 & 600 & 60 & 501.493 & -54.005 & 489.552 & -53.796 \\
\hline 27 & 10 & 600 & 90 & 304.478 & -49.671 & 331.343 & -50.406 \\
\hline
\end{tabular}

Note:

Er (15/15 wt\%): Erosion rate of SiC nanopowder filled 15/15 wt\% FSHC (mg/kg).

Er (20/20 wt\%): Erosion rate of SiC nanopowder filled 20/20 wt\% FSHC (mg/kg)
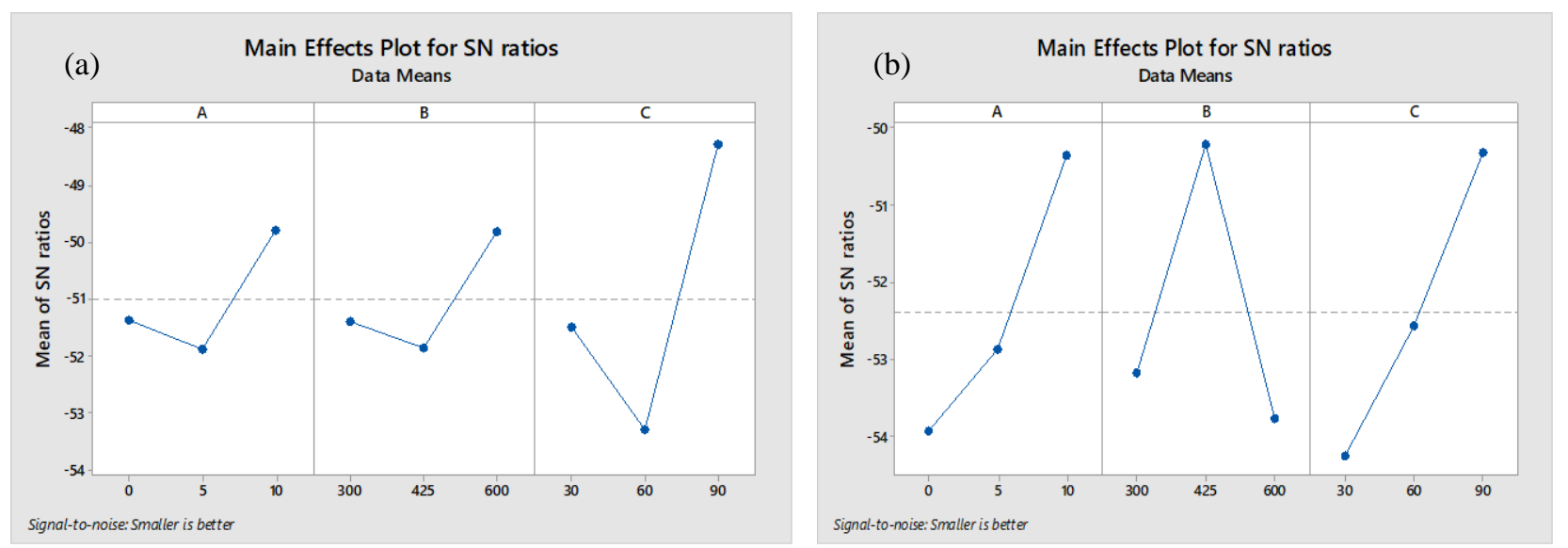

Figure 4: Effect of control factors on erosion rate (a) For SiC nanopowder filled 20/20 wt\% FSHC and (b) For SiC nanopowder filled 15/15 wt\% FSHC 
Table 5: ANOVA table for erosion rate for $\mathrm{SiC}$ nanopowder filled 15/15 wt \% FSHC

\begin{tabular}{|c|c|c|c|c|c|c|c|}
\hline $\begin{array}{c}\text { Sourc } \\
\mathrm{e}\end{array}$ & DOF & $\begin{array}{l}\text { Seq } \\
\text { SS }\end{array}$ & $\begin{array}{c}\text { Adj } \\
\text { SS }\end{array}$ & $\begin{array}{l}\text { Adj } \\
\text { MS }\end{array}$ & F & $\mathrm{P}$ & $\begin{array}{l}\text { Pc } \\
(\%)\end{array}$ \\
\hline A & 2 & 21.83 & 21.83 & $\begin{array}{c}10.91 \\
6\end{array}$ & $\begin{array}{c}0.8 \\
7\end{array}$ & $\begin{array}{c}0.45 \\
5\end{array}$ & 5.29 \\
\hline B & 2 & 20.59 & 20.59 & $\begin{array}{c}10.29 \\
6\end{array}$ & $\begin{array}{c}0.8 \\
2\end{array}$ & $\begin{array}{c}0.47 \\
4\end{array}$ & 4.99 \\
\hline $\mathrm{C}$ & 2 & $\begin{array}{c}116.9 \\
9\end{array}$ & $\begin{array}{c}116.9 \\
9\end{array}$ & $\begin{array}{c}58.49 \\
6\end{array}$ & $\begin{array}{c}4.6 \\
7\end{array}$ & $\begin{array}{c}0.04 \\
5\end{array}$ & $\begin{array}{c}28.3 \\
5\end{array}$ \\
\hline$A \times B$ & 4 & $\begin{array}{c}118.9 \\
2\end{array}$ & $\begin{array}{c}118.9 \\
2\end{array}$ & $\begin{array}{c}29.73 \\
1\end{array}$ & $\begin{array}{c}2.3 \\
7\end{array}$ & $\begin{array}{c}0.13 \\
9\end{array}$ & $\begin{array}{c}28.8 \\
2\end{array}$ \\
\hline$A \times C$ & 4 & 12.15 & 12.15 & 3.038 & $\begin{array}{c}0.2 \\
4\end{array}$ & $\begin{array}{c}0.90 \\
6\end{array}$ & 2.95 \\
\hline$B \times C$ & 4 & 21.92 & 21.92 & 5.479 & $\begin{array}{c}0.4 \\
4\end{array}$ & $\begin{array}{c}0.77 \\
9\end{array}$ & 5.31 \\
\hline Error & 8 & $\begin{array}{c}100.2 \\
1\end{array}$ & $\begin{array}{c}100.2 \\
1\end{array}$ & $\begin{array}{c}12.52 \\
6\end{array}$ & & & $\begin{array}{c}24.2 \\
9\end{array}$ \\
\hline Total & 26 & $\begin{array}{c}412.6 \\
2 \\
\end{array}$ & & & & & 100 \\
\hline
\end{tabular}

Table 6: ANOVA table for erosion rate for SiC nanopowder filled 20/20 wt \% FSHC

\begin{tabular}{cccccccc}
\hline Source & DOF & $\begin{array}{c}\text { Seq } \\
\text { SS }\end{array}$ & $\begin{array}{c}\text { Adj } \\
\text { SS }\end{array}$ & $\begin{array}{c}\text { Adj } \\
\text { MS }\end{array}$ & F & P & $\begin{array}{c}\text { Pc } \\
(\%)\end{array}$ \\
\hline A & 2 & 61.25 & 61.25 & 30.623 & 3.64 & 0.075 & 16.93 \\
B & 2 & 65.75 & 65.75 & 32.873 & 3.91 & 0.066 & 18.17 \\
C & 2 & 70.35 & 70.35 & 35.176 & 4.18 & 0.057 & 19.45 \\
$\mathrm{~A} \times \mathrm{B}$ & 4 & 61.04 & 61.04 & 15.259 & 1.81 & 0.22 & 16.87 \\
$\mathrm{~A} \times \mathrm{C}$ & 4 & 18 & 18 & 4.499 & 0.53 & 0.715 & 4.97 \\
$\mathrm{~B} \times \mathrm{C}$ & 4 & 18.06 & 18.06 & 4.515 & 0.54 & 0.714 & 4.99 \\
Error & 8 & 67.33 & 67.33 & 8.417 & & & 18.61 \\
Total & 26 & 361.77 & & & & & 100 \\
\hline
\end{tabular}

\section{Confirmation Experiment}

In order to forecast and confirmation of any design of experimental approach, an optimal combination of level of control factors are used. $A_{3} B_{3} C_{3}$ is arbitrary set of factor combination to study the confirmation experiment for SiC nanopowder filled 15/15 wt\% FSHC. Similarly, for SiC nanopowder filled 20/20 wt \% FSHC the arbitrary set of factor combination $\mathrm{A}_{3} \mathrm{~B}_{2} \mathrm{C}_{3}$ is taken.

Following equation can be used to predict the $\mathrm{S} / \mathrm{N}$ ratio for erosion rate;

For SiC nanopowder filled 15/15 wt\% FSHC;

$\bar{\eta}=\overline{\mathrm{T}}+\left[\left(\overline{\mathrm{A}_{9}}-\overline{\mathrm{T}}\right)+\left(\overline{\mathrm{B}_{2}}-\overline{\mathrm{T}}\right)\right]+\left[\left(\overline{\mathrm{A}_{3}} \overline{\mathrm{B}_{3}}-\overline{\mathrm{T}}\right)-\left(\overline{\mathrm{A}_{3}}-\overline{\mathrm{T}}\right)-\left(\overline{\mathrm{B}_{2}}-\right.\right.$ $\overline{\mathrm{T}})]+\left(\overline{\mathrm{C}_{3}}-\overline{\overline{\mathrm{T}}}\right)+\left[\left(\overline{\mathrm{B}_{3}} \overline{\mathrm{C}_{3}}-\overline{\mathrm{T}}\right)-\left(\overline{\mathrm{B}_{a}}-\overline{\mathrm{T}}\right)-\left(\overline{\mathrm{C}_{3}}-\overline{\mathrm{T}}\right)\right]$

For SiC nanopowder filled 20/20 wt\% FSHC;

$$
\begin{gathered}
\bar{\eta}=\overline{\mathrm{T}}+\left[\left(\overline{\mathrm{A}_{3}}-\overline{\mathrm{T}}\right)+\left(\overline{\mathrm{B}_{2}}-\overline{\mathrm{T}}\right)\right]+\left[\left(\overline{\mathrm{A}_{3}} \overline{\mathrm{B}_{2}}-\overline{\mathrm{T}}\right)-\left(\overline{\mathrm{A}_{3}}-\overline{\mathrm{T}}\right)-\left(\overline{\mathrm{B}_{2}}\right.\right. \\
-\overline{\mathrm{T}})]+\left(\overline{\mathrm{C}_{3}}-\overline{\overline{\mathrm{T}}}\right)+\left[\left(\overline{\mathrm{B}_{2}} \overline{\mathrm{C}_{3}}-\overline{\mathrm{T}}\right)-\left(\overline{\mathrm{B}_{2}}-\overline{\mathrm{T}}\right)-\left(\overline{\mathrm{C}_{3}}-\overline{\mathrm{T}}\right)\right]
\end{gathered}
$$

Using above prediction equations, erosion wear is found to be -41.306 db for SiC nanopowder filled 15/15 wt\% FSHC and $-47.236 \mathrm{db}$ for SiC nanopowder filled 20/20 wt\% FSHC. An error of $1.62 \%$ and $5.7 \%$ for the signal to noise ratio of erosion rate is observed for $\mathrm{SiC}$ nanopowder filled 15/15 wt\% and 20/20 wt\% FSHC respectively.

\section{CONCLUSION}

This analytical and experimental investigation on unfilled and SiC nanopowder filled FSHC has led to the following specific conclusions: Erosion characteristics of these composites can be efficiently analyzed by making use of Taguchi experimental design scheme. This study reveals that for similar test conditions 10wt\% SiC nanopowder filled 20/20 wt\% FSHC exhibits better wear resistance than those by unfilled and other composition of $\mathrm{SiC}$ nanopowder filled FSHC. Study of effect of impingement angle on erosion rate of the composites filled with different weight percentage of $\mathrm{SiC}$ nanopowder reveals the ductile nature with respect to erosion wear. Impingement angle $30^{\circ}$ resulted in the peak erosion rate. Unfilled composites have semi ductile behavior and peak erosion is found at $60^{\circ}$.

\section{REFERENCES}

1. Pool Erosive wear of composite materials. 107, 1-12 (1986).

2. Bayer, R. G. \& Consultant, T. Fundamentals of Wear Failures.

3. Materials, T. \& Company, I. w w w en te ch no lo g te ch no g.

4. Zahavi, J. - 190 0. 71, 179-190 (1981).

5. A, E. S. S., Tilly, G. P. \& Gas, N. Wear - Elsevier Sequoia S.A., Lausanne - Printed in the Netherlands 447. 16, 447-465 (1970).

6. Kim Solid particle erosion of CFRP composite with different laminate orientations. 267, 1922-1926 (2009).

7. Mahapatra Study on mechanical and erosion wear behavior of hybrid composites using Taguchi experimental design. Mater. Des. 30, 2791-2801 (2009).

8. Rajesh et al. Effect of impinging velocity on the erosive wear behaviour of polyamides. 37, 219-226 (2004).

9. Biswas et al.Tribo-performance analysis of red mud filled glass-epoxy composites using Taguchi experimental design. Mater. Des. 30, 2841-2853 (2009).

10. Gupta et al. Effect of Different Parameters on Mechanical and Erosion Wear Behavior of Bamboo Fiber Reinforced Epoxy Composites. 2011, 12-14 (2011).

\section{AUTHORS PROFILE}

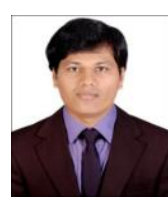

Ganesh Kalagi Sr. Assistant Professor, Mechanical Engineering Department, Shri Madhwa Vadiraja Institute of Technology \& Management, Bantakal, India Research Scholar, School of Mechanical Engineering, REVA University, Bengaluru, India Email: ganeshkalagi082@gmail.com

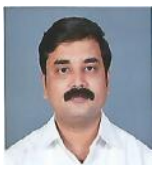

Rajashekar Patil Professor and Head of the department, School of Mechanical Engineering, CMR University, Chagalahatti, Bengaluru, India Email: eashan123@gmail.com 